\title{
Survey on underwater optical wireless communication: perspectives and challenges
}

Tejaswini R Murgod, S Meenakshi Sundaram

Department of Computer Science \& Engineering, GSSS Institute of Engineering \& Technology for Women, KRS Road, Metagalli, Mysuru, Karnataka, India

\begin{tabular}{l} 
Article Info \\
\hline Article history: \\
Received Sep 8, 2018 \\
Revised Nov 9, 2018 \\
Accepted Nov 23, 2018
\end{tabular}

\section{Keywords:}

Cross layer design

Localization algorithm

Routing algorithm

Underwater communication

\begin{abstract}
The demand for underwater communication is growing at a faster pace since few decades. Maximizing the communication performance and building efficient network architecture for underwater communication is a challenging task. Due to the reduced bandwidth, high error rate, noise, propagation delay, water currents and increased cost in the network topology, the existing communication techniques are not feasible for underwater communication. Research in high speed underwater transmission technology has become a primary need in today's world. By using underwater acoustic sensor network high transmission distance can be achieved but with lower data rates, high power consumption, larger delays and with higher cost. Underwater Optical Communication can be used to increase data rates and lower delays but it suffers from high attenuation due to which it cannot be used for data transfer over larger distances. Research in the area of hybrid sensor networks is a challenging task and has many open research challenges, which needs to be solved. In this paper we discuss the various architectures of underwater communication. Secirity, Reliable data transfer, congestion control and setting up a hybrid (optical and acoustic) communication system are some of the open research challenges indentified in this paper. A comparative study is made on different routing protocols and localization algorithms. The challenges faced by acoustic and optical communication are also discussed.
\end{abstract}

Copyright () 2019 Institute of Advanced Engineering and Science. All rights reserved.

\section{Corresponding Author:}

Tejaswini R Murgod,

Department of Computer Science and Engineering,

GSSS Institute of Engineering \& Technology for Women,

KRS Road, Metagalli, Mysuru, Karnataka, India.

Email: tejaswinirmurgod@gmail.com

\section{INTRODUCTION}

Oceans are composed of water and other elements. Based on the physical and biological conditions, oceans are divided into different zones. At the surface zone the temperature \& salinity are relatively constant. As the depth increases the temperature \& solar energy gets decreased.

Research in underwater communication has gained popularity, in the areas of pollution management, biological monitoring, disaster prevention and increasing terrorist activities under sea. Setting up a wired connection under sea is not feasible due to the increased cost of laying down the cables. Wireless communication can be used to transfer information among the nodes. Under the sea, the water pressure is high and due to turbines limited band width; high error rate and propagation delay, as a result establishing a reliable and secure communication is difficult as shown in Figure 1 [1]. 


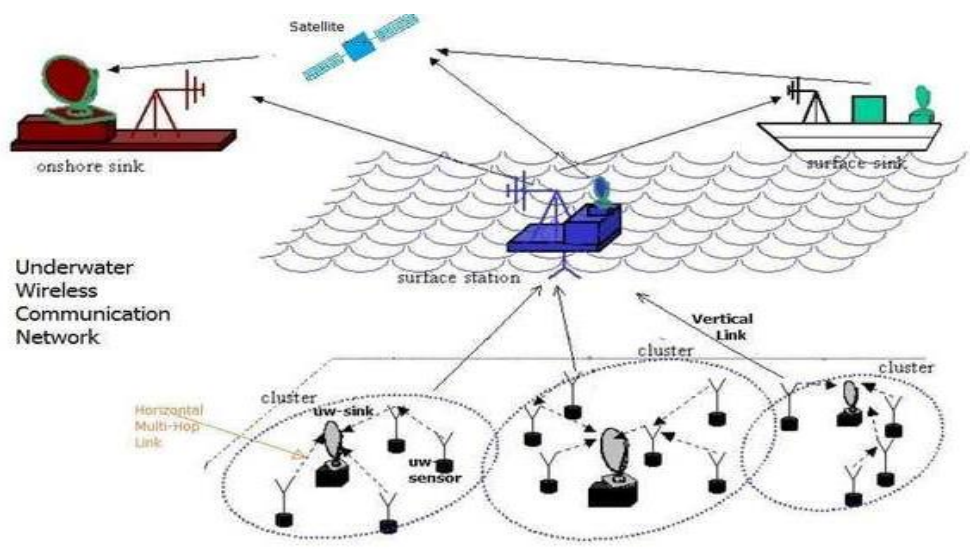

Figure 1. Underwater sensor network

EM waves propagate at longer distances through conductive sea water at very low frequencies (i.e. 30 to $300 \mathrm{~Hz}$ ). This needs large antenna and high power for transmission. Hence it is not ideal for underwater communication. In contrast to EM waves, optical waves do not suffer from very high attenuation. However optical communication under water suffers from scattering loss. Moreover it needs high precision narrower laser beams for carrying the information. Hence optical waves are suitable for short range communication in underwater environment.

The underwater wireless optical communication is a kind of communication mode with light wave as the carrier of information. Sullian and Dimtley et al. in 1963 found in the study of propagation characteristics of light waves, that the ocean has attenuation is in the order of $450-550 \mathrm{~nm}$ for blue light. The green light in seawater is much smaller than the other bands of light as shown in Figure 2. This significant physical discovery laid a solid foundation to solve long term underwater target detection, communication and the other essential problems [2-3].

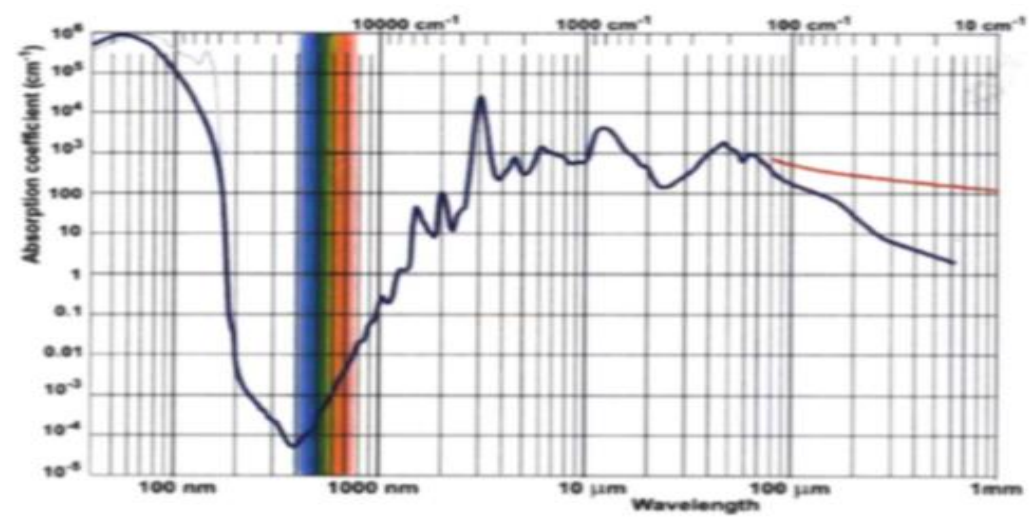

Figure 2. Attenuation of light wave in seawater

As the bandwidth and energy consumption of nodes are the critical issues for underwater communication, traditional layered approach is not feasible. Proposing different Medium Access Control (MAC) protocols, establishing cross layer designs are still a few open research challenges. [4]

In this paper we explore the challenges faced in underwater communication. Section 2 highlights the different underwater network architectures, reliability and efficiency issues in underwater communication. Section 3 focuses on analysis of different routing and localization algorithms. Challenges faced by acoustic communication are listed in Section 4. Section 5 discusses the challenges faced by optical communication and some of the open research challenges are discussed in Section 6. 


\section{RELATED WORKS}

\subsection{Network Architecture of Underwater Communication}

Saunvit Pandya et.al [5] have designed a protocol where acoustic communication could be integrated into an application centered subsystem. In this architecture the nodes have acted as a continuous transmitter and the base station has acted as a receiver. Majid Hamidzadeh et.al [6] have proposed an architecture where nodes were grouped into clusters at different layers. A tree model was constructed where the sensor nodes at the root level and the child nodes were linked like a wheel. Based on the location of the nodes and the number of sink nodes one sensor node was selected as the cluster head. This architecture improved the performance, scalability and flexibility of underwater networks where the regular network was imagined as a hierarchical structure.

Energy consumption for underwater communication is more compared to terrestrial communication. Donghoon Kim [7] proposed an architecture where the nodes were differentiated based on their functionalities. The offshore nodes sent a signal to the sensor node under the sea. Based on the distance between the source and the sink, the relay nodes were used as the intermediate nodes.

Seema Verma et.al [8] proposed a dynamic 3D architecture where self configuring sensor nodes were plotted on different vertical and horizontal levels. Data was measured at different intervals to reduce the energy utilization. When the measured data was not within the specified range then only the data was forwarded to the base station in order to save the energy and power consumption. This architecture reduced the transmission rate, energy and transmission time by inculcating multi-hop communication. [9]

\subsection{Reliablity in Underwater Communication}

The fundamental requirement of UWC is reliable delivery of data. Reliability of the data can be increased by Forward Error Correction (FEC), multipath transmission, redundancy etc. Underwater communications have limited resource, low bandwidth and high error rates due to which achieving reliability is a challenging task.

Rehan Qayyum et.al [10] have analyzed the different reliability schemes like redundant transmission over multiple paths. For the FEC redundant symbols were attached to the data to achieve high reliability. Due to redundant multipath, transmission overhead delays were introduced. Yao Lu [11] proposes a redundant unshared model and redundant shared model. In the redundant unshared model every node had ' $n$ ' redundant nodes and in redundant shared model only nodes that were near the surface had ' $n$ ' redundant nodes. Muhammad Sabbir Alam [12] proposed an electromagnetic wave based navigation system. The cluster head and base station were located on the surface. Autonomous vehicles moved near the senor nodes to collect the data and forwarded it to the cluster head and base station. Through simulations it was shown that EM based navigation increased reliability for shorter transmission range networks.

\subsection{Efficiency in Underwater Communication}

The common problem in a modern network is traffic congestion. An efficient network reduces traffic congestion and delivers the data to the destination.

Nitin Goyal [13] proposed an energy efficient architecture where fuzzy logic concept is used to determine the cluster head and cluster size. The network was divided into larger group of clusters where, intra and inter cluster communication was used to transfer the data between the source and the sink node. Using fuzzy logic, optimal number of cluster heads was found in order to have an efficient network which reduced the energy consumption of nodes and end to end delay[14].

Sumi A. Samad [15] proposed a protocol where efficiency of the network was increased by cross layer design. In the latency detection phase, each node calculated the latency to its neighboring node and was passed by the MAC layer to the physical layer. This interaction optimized the transmission power. The node first sent a reservation message to the receiver and after getting an acknowledgement the time slot was reserved for communication.

\section{ANALYSIS AND DISCUSSIONS}

In this section based on the related works analysis has been carried out for routing protocols and localization algorithm.

\subsection{Analysis of Different Routing Protocols}

In the underwater communication networks, because of long propagation delays, noise, low bandwidth and mobility of nodes routing the data to the destination node is a challenging issue. Various routing protocols are proposed in order to route the data to the correct destination with minimum number of hop count $\&$ without losing the quality of the data. 
Manjula et.al [16] proposed a cluster agent based routing approach where agents are defined at every sensor node for event detection, cluster formation, head selection, updating neighbor information and network maintenance. Every node periodically collects information about temperature, pressure, salinity and compares them with the threshold value. If the sensed values are greater than the threshold, an event is triggered. Each event is classified as critical and non critical. The Cluster Head $(\mathrm{CH})$ is selected based on the time required for information transmission, energy requirement and link quality. The $\mathrm{CH}$ aggregates data collected from various nodes and sends it to all the other nodes in the cluster. As the route discovery is done by the cluster head a reliable path is established.

Guangjie Han [17] proposed a link based reverse routing protocol where each node analyzes the link state information through a neighbor table which consists of sending node ID, receiving node ID and the link state information. A node extracts the sender node ID from the hello packet and receiver node ID from the acknowledge packet and updates its neighbor table. A symmetric link is established if both sender and receiver ID are present in the table otherwise an asymmetric link is established if only sender can send a message to receiver or only receiver can receive a message from the sender.

Shalli Rani [18] proposed a cluster based routing mechanism where the ocean is divided into multiple clusters. The cluster heads, cluster coordinators and relay nodes are used to route the data to different nodes within the network. Optimal relay nodes are selected to improve the reliability of the network. The confidence value for each node is set based on the link quality, hop count, residual energy and buffer space. The node with the higher confidence value is elected as a relay node. This methodology improves reliability, energy utilization and packet delivery ratio.

Nadeem Javaid et.al [19] proposed a routing protocol where the entire network is divided into distinct regions and cooperative protocol is used for communication where relay nodes amplify the signal and pass to the destination. To reduce the packet drop ration sink nodes are made mobile and they travel in horizontal and vertical direction to cover the entire network.

A location free reliable and energy efficient pressure based routing protocol is proposed by Ahmad Khasawneh et.al [20] where link quality, depth information and residual energy parameters are used for balancing energy consumption and reliable data delivery. Triangular metric is used as link quality estimator, after estimating the link quality and residual energy of the nodes; the packets are forwarded to the next hop which is closer to the destination having best link quality and maximum residual energy.

Stefano et.al [21] proposed a routing algorithm where the link quality was taken into consideration for selecting a node. The history of the successful transmission was taken into account while selecting the next node in the path. To avoid pitfalls and to route the data in the shadow zone, a simple hop count topology was used. Short control messages were used to select the channel for transmission. Due to increase in the traffic and packet size, the collision also increased; as the transmission was based on the link quality information the collision rate had substantially reduced.

The Table 1 shows a comparative study of different routing protocols based on various factors like bandwidth, data transmission rate, throughput, network lifetime etc.

Table 1. Comparison of Different Routing Protocols

\begin{tabular}{|c|c|c|c|c|c|c|c|c|}
\hline Protocol/ architecture & $\begin{array}{l}\text { Energy } \\
\text { Consumption }\end{array}$ & $\begin{array}{l}\text { Cluster/ } \\
\text { single }\end{array}$ & $\begin{array}{l}\text { Packet } \\
\text { Delivery } \\
\text { Ration }\end{array}$ & $\begin{array}{l}\text { Data } \\
\text { Transmission } \\
\text { Rate }\end{array}$ & $\begin{array}{l}\text { Packet } \\
\text { Drops }\end{array}$ & $\begin{array}{l}\text { Location } \\
\text { Awareness }\end{array}$ & $\begin{array}{l}\text { Network } \\
\text { Lifetime }\end{array}$ & Throughput \\
\hline $\begin{array}{l}\text { ABA (Manjula } \\
\text { et.al.,2017) [16] }\end{array}$ & Low & Cluster & High & High & Low & Yes & Medium & High \\
\hline $\begin{array}{l}\text { AREP (Guangjie Han } \\
\text { et.al.,2017) [17] }\end{array}$ & Low & Single & High & High & Low & Yes & $\mathrm{n} / \mathrm{a}$ & Low \\
\hline $\begin{array}{l}\text { E-CBCCP (Shalli Rani } \\
\text { et.al., 2017) [18] }\end{array}$ & Low & Cluster & High & High & Low & No & $\mathrm{n} / \mathrm{a}$ & Medium \\
\hline $\begin{array}{l}\text { RBCRP (Nadeem Javaid } \\
\text { et.al., 2017) [19] }\end{array}$ & High & Single & Medium & Medium & Low & No & High & High \\
\hline $\begin{array}{l}\text { RE-PBR (Ahmad } \\
\text { Khasawneh et.al., 2017) } \\
\text { [20] }\end{array}$ & Low & Single & High & Medium & Low & No & High & Medium \\
\hline $\begin{array}{l}\text { CARP ( Stefano } \\
\text { et.al.,2015) }[21]\end{array}$ & Low & Single & High & Medium & Low & Yes & Low & Medium \\
\hline $\begin{array}{l}\text { PRUSN(Uichin Lee } \\
\text { et.al., 2010) [22] }\end{array}$ & High & Single & Medium & Medium & Medium & No & Low & Medium \\
\hline $\begin{array}{l}\text { AHH-VBE ( Haitao Yu } \\
\text { et.al., 2014) [23] }\end{array}$ & Low & Single & Medium & Medium & Medium & Yes & Low & Medium \\
\hline $\begin{array}{l}\text { H2DAB (Muhammad } \\
\text { Ayaz et.al., 2011) [24] }\end{array}$ & High & Single & Medium & Medium & Low & No & Low & Low \\
\hline $\begin{array}{l}\text { PULRP (Sarath Gopi } \\
\text { et.al.,2008) [25] }\end{array}$ & High & Single & Medium & Low & High & No & Low & Low \\
\hline
\end{tabular}

Survey on underwater optical wireless communication: perspectives and challenges (Tejaswini R Murgod) 


\subsection{Analysis of Different Localization Algorithms}

As the GPS Signal is low underwater, locating the nodes is a challenging task. Due to high water pressure and turbines the nodes continuously change their location. Various localization algorithms have been proposed to determine the physical location of the sensor nodes. Localization algorithms can be classified as range based and range free algorithms.

Anjana et.al [26] proposed a fault resilient algorithm where each sensor nodes maintains the location information of its neighboring node and continuously monitors the node mobility. A time synchronized anchor node is used as a base station which has GPS receiver and can transmit radio and acoustic signals. The A-node periodically broadcasted a packet to the S-nodes deployed underwater; upon successful receipt of the packet the S-node started computing its location.

Eliyeh [27] proposed an algorithm where localization and time synchronization were jointly performed. The algorithm worked in five phases, in the first phase the sensor nodes collected the timestamp information and its initial position from the anchor node. By using the timestamp information collected in the first phase, least square and weighted least square estimators were used to estimate the clock skew and offset in the second phase. The propagation delay was calculated in the third phase by compensating the speed, as it varied with depth temperature and salinity. The sound speed between sensor nodes and anchor nodes was calculated in phase four. Phase five was an iterative phase where the calculated sound speed was fed as an input to phase two and the updated clock skew and sound velocity were used to calculate the propagation delay.

Jingjie Gao [28] proposed a hybrid localization algorithm where the entire network was is different stages based on the hop counts from the anchor nodes. Different stages adopted different localization methods. Anchor nodes were deployed at the sea surface and their location were known, where as ordinary nodes are deployed at different stages.

Patrick Carroll [29] proposed a localization algorithm for mobile node via distributed antenna system. The modem used here had a capacity to estimate the doppler scaling factor of the received signal. The accuracy in the position estimation was increased by combining the time of arrival and doppler speed information into a single message. At some time internal the active node sent a message to all listening nodes to perform the localization process. Based on the received waveform, each node estimated the doppler speed.

Mukesh Beniwal [30] proposed an algorithm where the locations of few nodes were known in advance. The mobile beacons were used to dive in vertical direction into the sea. These mobile beacons have GPS receiver at the surface and as they drive deep into the sea only the $\mathrm{Z}$ coordinate value changes. These beacons broadcasted a message at regular intervals and the sensor nodes listened to the broadcast message and calculate their distance from listening to the three beacons. The Table 2 summarizes and compares the different localization algorithms

\section{CHALLENGES FACED BY UNDERWATER ACOUSTIC COMMUNICATION}

a) Low Data Rates: The speed at which sound travels through water is highly dependent on temperature, pressure and salinity level. Underwater acoustic channel have limited bandwidth, as the range of distance increases the bandwidth decreases which affects the throughput of the network.

b) Multipath fading: Multipath is the propagation phenomenon that results in signals reaching the receiving antenna by two or more paths. The effects of multipath include constructive and destructive interference, and phase shifting of the signal. The multipath depends on the link configuration.

c) Doppler: The motion of the sea surface and the low speed of sound penetration introduces a large Doppler spread, and results in a fast-fading frequency-selective behaviour (or temporal and spatial variability) of the underwater acoustic channel.

d) Noise: Noise in acoustic channel can be classified as ambient noise and specific noise. Ambient noise is the noise which comes from ice breaking in Polar Regions, turbulence, breaking waves, rain etc, where as specific noise in man-made noise which is caused by pumps, gears, power plants, ship movement etc. 
Table 2. Summary of the Different Localization Algorithms

\begin{tabular}{|c|c|c|c|c|c|c|c|c|c|c|}
\hline $\begin{array}{l}\text { Refer } \\
\text { ence }\end{array}$ & $\begin{array}{c}\text { Publishing } \\
\text { Date }\end{array}$ & Type & $\begin{array}{l}\text { Static/Mobile } \\
\text { Reference }\end{array}$ & $\begin{array}{l}\text { No of } \\
\text { Nodes }\end{array}$ & Dimension & Depth & Sound Speed & $\begin{array}{l}\text { Localization } \\
\text { error }\end{array}$ & Challenges Addressed & Limitations \\
\hline 26 & 2017 & $\begin{array}{l}\text { Range } \\
\text { Based }\end{array}$ & $\begin{array}{l}\text { Static: } \\
\text { Anchor } \\
\text { Node } \\
\text { Mobile: } \\
\text { Sensor node }\end{array}$ & 50 & $\begin{array}{l}500 * 500 \\
* 500 \mathrm{~m}\end{array}$ & 50 & $\begin{array}{l}\text { Assumed } \\
\text { Static }\end{array}$ & $\begin{array}{l}\text { Average } \\
\text { error }=1.3 \\
\mathrm{~km}\end{array}$ & $\begin{array}{l}\text { - Anchor nodes are } \\
\text { fault tolerant } \\
\text { - Energy utilization } \\
\text { is reduce }\end{array}$ & $\begin{array}{l}\text { - Senor nodes are not } \\
\text { fault tolerant } \\
\text { - Maintaining } \\
\text { information about } \\
\text { neighbour nodes can } \\
\text { be difficult as nodes } \\
\text { are mobile }\end{array}$ \\
\hline 27 & 2017 & $\begin{array}{l}\text { Range } \\
\text { Based }\end{array}$ & $\begin{array}{l}\text { Static: } \\
\text { Anchor } \\
\text { node } \\
\text { Mobile : } \\
\text { Ordinary } \\
\text { node with } \\
\text { uniform } \\
\text { distributed } \\
\text { speed [-5,5] } \\
\text { knots }\end{array}$ & 4 & $\begin{array}{l}1000 * \\
1000 * 30 \\
0\end{array}$ & $\begin{array}{l}300 \\
\mathrm{~m}\end{array}$ & $\begin{array}{l}\text { Avg } \\
\text { sound } \\
\text { speed : } \\
1500 \mathrm{~m} / \mathrm{s}\end{array}$ & $\begin{array}{l}\text { Represented } \\
\text { as a function } \\
\text { of : } 1 / \boldsymbol{\sigma} 2\end{array}$ & $\begin{array}{l}\text { - Localization and } \\
\text { synchronization } \\
\text { are done together }\end{array}$ & $\begin{array}{l}\text { - Setting the threshold } \\
\text { value should be done } \\
\text { properly in order to } \\
\text { stop the iterative } \\
\text { process. } \\
\text { - Energy consumption } \\
\text { is more. }\end{array}$ \\
\hline 28 & 2017 & $\begin{array}{l}\text { Predic } \\
\text { tion } \\
\text { Based }\end{array}$ & $\begin{array}{l}\text { Static : } \\
\text { Anchor } \\
\text { Node } \\
\text { Mobile : } \\
\text { Ordinary } \\
\text { nodes }\end{array}$ & 100 & $\begin{array}{l}2000 * \\
2000 \mathrm{~m}\end{array}$ & $\begin{array}{l}200 \\
m\end{array}$ & $\mathrm{n} / \mathrm{a}$ & $\begin{array}{l}\text { As } \\
\text { communicati } \\
\text { on range } \\
\text { increases } \\
\text { localization } \\
\text { error } \\
\text { increases }\end{array}$ & $\begin{array}{l}\text { - Localization does } \\
\text { not need prior } \\
\text { knowledge of } \\
\text { sound speed } \\
\text { - Communication } \\
\text { cost is reduced }\end{array}$ & $\begin{array}{l}\text { - More number of } \\
\text { reference nodes are } \\
\text { used } \\
\text { - Relocalization } \\
\text { procedure at different } \\
\text { stages is time } \\
\text { consuming. }\end{array}$ \\
\hline 29 & 2016 & $\begin{array}{l}\text { Range } \\
\text { Based }\end{array}$ & $\begin{array}{l}\text { Mobile: } \\
\text { Anchor } \\
\text { nodes }\end{array}$ & 4 & $\begin{array}{l}\text { Pool test } \\
\text { is done } \\
\text { with grid } \\
\text { dimensio } \\
\mathrm{n}: \\
(72,25,10 \\
)\end{array}$ & $\begin{array}{l}300 \\
m\end{array}$ & $\begin{array}{l}\text { Assumed } \\
\text { Static }\end{array}$ & $\mathrm{n} / \mathrm{a}$ & $\begin{array}{ll}\text { - Accuracy } & \text { in } \\
\text { location } & \text { is } \\
\text { increased } & \end{array}$ & $\begin{array}{l}\text { - An assumption is } \\
\text { made as all antenna } \\
\text { nodes knows their } \\
\text { perfect location and } \\
\text { are all globally time } \\
\text { synchronized, which } \\
\text { is difficult to achieve. } \\
\text { - Fault handling is not } \\
\text { addressed. }\end{array}$ \\
\hline 30 & 2016 & $\begin{array}{l}\text { Range } \\
\text { Free }\end{array}$ & $\begin{array}{l}\text { Static: } \\
\text { Sensor } \\
\text { Nodes } \\
\text { Mobile: } \\
\text { Beacons }\end{array}$ & 250 & $\begin{array}{l}150 * 250 \\
\mathrm{~m}\end{array}$ & $\begin{array}{l}250 \\
\mathrm{~m}\end{array}$ & $1500 \mathrm{~m} / \mathrm{s}$ & $\mathrm{n} / \mathrm{a}$ & $\begin{array}{l}\text { - Localization is } \\
\text { done without the } \\
\text { need of time } \\
\text { synchronization }\end{array}$ & $\begin{array}{l}\text { - Localization ration } \\
\text { decreases from } 90 \text { to } \\
65 \% \text { as the beacon } \\
\text { interval increases } \\
\text { - More energy is } \\
\text { consumed if the } \\
\text { transmission range is } \\
\text { considered at higher } \\
\text { level }\end{array}$ \\
\hline 31 & 2013 & $\begin{array}{l}\text { Range } \\
\text { Based }\end{array}$ & $\begin{array}{l}\text { Nodes are } \\
\text { mobile }\end{array}$ & 100 & $\begin{array}{l}1000 \mathrm{~m} \\
* 1000 \mathrm{~m} \\
* 20 \\
\text { regions }\end{array}$ & $\begin{array}{l}360 \\
\mathrm{~m}\end{array}$ & $\mathrm{n} / \mathrm{a}$ & $\begin{array}{l}\text { Average } \\
\text { Error: } 2.63 \mathrm{~m}\end{array}$ & $\begin{array}{l}\text { - Localization is } \\
\text { done without the } \\
\text { use of anchor } \\
\text { nodes }\end{array}$ & $\begin{array}{l}\text { - Sensors are allowed } \\
\text { to move only within } \\
\text { the active restricted } \\
\text { area, but where as in } \\
\text { ocean the nodes with } \\
\text { the waves and } \\
\text { current. } \\
\text { - To locate the nodes } \\
\text { the location of at } \\
\text { least one node should } \\
\text { be known in advance. }\end{array}$ \\
\hline 32 & 2013 & $\begin{array}{l}\text { Range } \\
\text { Free }\end{array}$ & $\begin{array}{l}\text { Static: } \\
\text { Sensor } \\
\text { Nodes }\end{array}$ & 500 & $\begin{array}{l}1000^{*} \\
200^{*} \\
200 \mathrm{~m}\end{array}$ & $\mathrm{n} / \mathrm{a}$ & $\mathrm{n} / \mathrm{a}$ & $\begin{array}{l}\text { Localization } \\
\text { error } \\
\text { increases } \\
\text { with higher } \\
\text { node } \\
\text { mobility. }\end{array}$ & $\begin{array}{l}\text { - Can be applied to } \\
\text { large scale mobile } \\
\text { networks. } \\
\text { - Energy efficiency } \\
\text { is increased. }\end{array}$ & $\begin{array}{l}\text { - Acoustic vehicles are } \\
\text { used due to which the } \\
\text { cost may be } \\
\text { increased. }\end{array}$ \\
\hline 33 & 2012 & $\begin{array}{l}\text { Range } \\
\text { Based }\end{array}$ & & 250 & $\begin{array}{l}1000^{*} \\
1000 \mathrm{~m}\end{array}$ & $\begin{array}{l}400 \\
0 \\
\text { mtrs }\end{array}$ & $1500 \mathrm{~m} / \mathrm{s}$ & $\begin{array}{l}\text { Average } \\
\text { error } \\
\text { increases } \\
\text { with the } \\
\text { increase in } \\
\text { temperature }\end{array}$ & $\begin{array}{l}\text { - Considers harsh } \\
\text { underwater } \\
\text { environment while } \\
\text { calculating the } \\
\text { localization error }\end{array}$ & $\begin{array}{l}\text { - Requires precise time } \\
\text { synchronization } \\
\text { between the nodes }\end{array}$ \\
\hline
\end{tabular}

\section{CHALLENGES FACED BY UNDERWATER OPTICAL COMMUNICATION}

Optical signals between 400 to $700 \mathrm{~nm}$ can be used for underwater communication for faster propagation, but optical transmitter and receiver must be placed at shorter distances. Optical transducers if placed at larger distances than because of high turbulence performance may be degraded. Table 3 shown specifies the absorption, scattering and attenuation level for different types of water. As shown in Table 4. 
Table 3. Relationship between Range and Bandwidth in Underwater Acoustic Network

\begin{tabular}{cc}
\hline Range $[\mathrm{km}]$ & Bandwidth $[\mathrm{kHz}]$ \\
\hline$<0.1$ & $>100$ \\
$0-1.1$ & $20-50$ \\
$1-10$ & 10 \\
$10-100$ & $2-5$ \\
1000 & $<1$ \\
\hline
\end{tabular}

Table 4. Absorption Scattering and Attenuation Level for Different Types of Water

\begin{tabular}{cccc}
\hline Water Type & Absorption & Scattering & Attenuation \\
\hline Pure sea water & 0.0405 & 0.0025 & 0.043 \\
Clean water & 0.114 & 0.037 & 0.151 \\
Coastal water & 0.179 & 0.219 & 0.298 \\
Turbid harbor & 0.266 & 1.824 & 2.19 \\
\hline
\end{tabular}

Though by using optical communication the propagation delay may be reduced, the optical communication shows less performance for deep sea or shallow water. The attenuation is also quite high when the turbid increases [34-35].

\section{OPEN RESEARCH CHALLENGES}

a) Security: Underwater sensor nodes have limited energy, computation and communication capabilities so the senor nodes need more protection than the nodes in terrestrial area. Denial of Service attack is a critical issue in underwater communication which may disturb the network collaboration. New techniques must be proposed in order the secure the network from DoS attack.

b) Reliable Data transfer: Underwater the data transfer can be either end-to-end or hop-by-hop. TCP can be used for end-to-end approach, but various problems may incur in layered approach. In underwater the propagation time is much larger than the transmission time which increases link error rates. Optical waves and radio waves do not propagate well underwater so most underwater communication uses acoustic waves for data transfer. The propagation speed of acoustic waves is $1500 \mathrm{~m} / \mathrm{s}$ which is much slower than optical and radio waves about $2.25 * 10^{8}$. Sound waves are easily affected by angle of incidence, reflection, temperature salinity which causes multipath fading.

c) Traffic congestion control: Acoustic transducers can transmit at high rate but cannot receive at the same rate because they are half duplex, they cannot simultaneously transmit and receive. Collision free multiple access is a challenging issue in underwater communication. Efficient collision resolution protocols can be proposed in order to handle the conflicts within the network.

d) Hybrid underwater wireless communication: High speed underwater wireless transmission is the urgent requirement in today's research which can be achieved by optical communication, but it is used for shorter distances. For large distances acoustic communication is used but because of low bandwidth propagation speed is decreased. So a hybrid optical-acoustic communication can be proposed in order to achieve high speed transmission for larger distances.

\section{CONCLUSION}

An efficient and reliable underwater communication is the basic requirement in today's communication system. Various architectures have been proposed to increase the reliability and throughput of the communication channel. In this paper a broad introduction of underwater communication system is provided discussing various architectures. Reliability and efficiency are the important needs of any communication system. Different methodologies that can be used to improve reliability and efficiency are also discussed.

In this paper, an attempt is made to make rigorous survey of existing routing mechanisms. Each routing protocol is carefully analyzed on various parameters like packet delivery ratio, energy consumption, transmission rate, packet drops, network lifetime and throughput. Almost all routing protocols use acoustic waves for communication. The major drawback of acoustic waves is transmission delays and high error rate. As an alternate optical communication can be used which achieves high transmission rate but it suffers from attenuation, due to which it cannot be used for larger transmissions. This motivates researches to explore a hybrid optical-acoustic approach. In recent years very less work in carried on hybrid approach.

Security plays an important role in any communication system. Underwater sensor network must be secured from the attacks of the intruder. Reliable data transfer, congestion control and setting up a hybrid 
(optical and acoustic) communication system are some of the open research challenges indentified in this paper. A comparative study of different localization algorithms is also made in this paper. Challenges addressed by different algorithms are discussed in detail. Also the challenges faced by underwater acoustic and optical communication are discussed.

\section{REFERENCES}

[1] Ahmed Mahdy and Jitender S. Deogun, "Wireless Optical Communications: A Survey" 2399-2404.

[2] "E-ITRC protocol with Long \& Adjustable range on Underwater Acoustic Sensor Network", IEEE 21st International Conference on Advanced Information Networking and Applications, 604, 665-672, 2007.

[3] Haziel Latupapua1, Andrias I Latupapua2, Abdi Wahab3, Mudrik Alaydrus4, "Wireless Sensor Network Design for Earthquake's and Landslide's Early Warnings", Indonesian Journal of Electrical Engineering and Computer Science(IJEECS) Vol. 11, No. 2, August 2018, pp. 437 445.

[4] Zabih Ghassemlooy, Murat Uysal, Julian Cheng, "Emerging Optical Wireless Communications-Advances and Challenges", IEEE Journal On Selected Areas In Communications, Vol. 33, NO. 9, SEPTEMBER 2015.

[5] Saunvit Pandya, Jonathan Engel, Jack Chen, Zhifang Fan, Chang Liu, "CORAL: Miniature Acoustic Communication Subsystem Architecture for Underwater Wireless Sensor Networks", IEEE Sensors, 163-166, 2005.

[6] Majid Hamidzadeh, Nosratallah Forghani, Ali Movaghar, "A New Hierarchal and Scalable Architecture for Performance Enhancement of Large Scale Underwater Sensor Networks", IEEE Symposium on Computers \& Informatics, 55, 520-525, 2011.

[7] Mandar Chitre, Lee Freitag, Ethem Sozer, Shiraz Shahabudeen, Milica Stojanovic, John Potter, "An Architecture for Underwater Networks", IEEE OCEANS 2006 - Asia Pacific - Singapore, 1-5, 2006.

[8] Seema Verma, Prachi, "Communication Architecture for Underwater Wireless Sensor Network", Computer Network and Information Security, 6, 67-74, 2015.

[9] Burhan Ul Islam Khan, Rashidah Funke Olanrewaju, Farhat Anwar, Athaur Rahman Najeeb, Mashkuri Yaacob, "A Survey on MANETs: Architecture, Evolution, Applications, Security Issues and Solutions", Indonesian Journal of Electrical Engineering and Computer Science (IJEECS) Vol. 12, No. 2, November 2018, pp. 832 842.

[10] Rehan Qayyum, Adnan Iqbal and Hassaan Khaliq Qureshi, "Performance Analysis of Data Delivery Reliability Schemes in Underwater Sensor Networks", 20th IEEE Symposium on Computers and Communication, 1020-1025, 2015.

[11] Yao Lu1 Zhong de-huan2 Yang jian-jun3, "Reliability Redundancy design of Underwater Sensor Networks", IEEE 2010 2nd International Conference on Information Engineering and Computer Science, 44, 1-4, 2010.

[12] Muhammad Sabbir Alam, Md. Farhad Hossain, Kumudu Munasinghe, and Abbas Jamalipour, "Reliability and Delay Analysis of AUV Navigation System Using EM Wave Based Underwater Sensor Network", IEEE 2015 9th International Conference on Signal Processing and Communication Systems, 30, 1-6, 2015.

[13] Nitin Goyal, Mayank Dave, Anil Kumar Verma2, "Energy Efficient Architecture for Intra and Inter Cluster Communication for Underwater Wireless Sensor Networks", Wireless Pers Commun 89:687-707.

[14] Yatendra Singh Bhandari, Yashwant Singh Chauhan, PritiDimri, "Modelling of Time Efficiency in Heterogeneous and Adhoc Networks", Indonesian Journal of Electrical Engineering and Computer Science (IJEECS) Vol. 12, No. 1, October 2018, pp. 147 154.

[15] Sumi A. Samad, S.K. Shenoy, and G. Santhosh Kumar, "Improving Energy Efficiency of Underwater Acoustic Sensor Networks Using Transmission Power Control: A Cross-Layer Approach", Springer-Verlag Berlin Heidelberg, 93-101, 2011.

[16] Manjula R. Bharamagoudra, SunilKumar S. Manvi, Bilal Gonen, "Event Driven Energy Depth and channel aware routing for underwater acoustics sensor networks Agent oriented clustering based approach", Computers and Electrical Engineering,58,1-19,2017.

[17] Guangjie Han,Li Liua, Na Baoa, Jinfang Jianga, Wenbo Zhangb, Joel J.P.C. Rodrigues, "AREP: An asymmetric link-based reverse routing protocol for underwater acoustic sensor networks", Journal of network and computer applications, 2-8,2017.

[18] Shalli Rania, Syed Hassan Ahmedb, Jyoteesh Malhotrac, Rajneesh Talwar, "Energy efficient chain based routing protocol for underwater wireless sensor networks", Journal of Networks and Computer Applications, 1-9, 2016.

[19] Nadeem Javaida,Sheraz Hussaina, Ashfaq Ahmada, Muhammad Imranb, Abid Khana, Mohsen Guizani, "Region based cooperative routing in underwater wireless sensor networks", Journal of Networks and Computer Applications,2-11, 2016.

[20] Ahmad Khasawneh, Muhammad Shafie Bin Abd Latiff, Omprakash Kaiwartya, Hassan Chizari, "A reliable energy-efficient pressure-based routing protocol for underwater wireless sensor network", 2-15, 2017.

[21] Stefano Basangi, Chiara Petrioli, Roberto Petroccia, Daniele Spaccini, "CARP: Channel aware routing protocol for underwater acoustic wireless network" Adhoc Networks, 34, 92-104, 2015.

[22] Uichin Lee, Paul Wang, Youngtae Noh, Luiz F. M. Vieira, Mario Gerla, Jun-Hong Cui, "Pressure Routing for Underwater Sensor Networks", IEEE INFOCOM, 2010.

[23] Haitao Yu, Nianmin Yao, Jun Liu, "An adaptive routing protocol in underwater sparse acoustic sensor networks, Adhoc Networks,121-143, 2015.

[24] Muhammad Ayaz, Azween Abdullah, Ibrahima Faye, Yasir Batira, "An efficient Dynamic Addressing based routing protocol for Underwater Wireless Sensor Networks", Computer Communications, 475-486,2012. 
[25] Sarath Gopi, G. Kannan, Deepthi Chander, U. B. Desai and S. N. Merchant, "PULRP: Path Unaware Layered Routing Protocol for Underwater Sensor Networks", publication in the ICC proceedings, 3141- 3145, 2008.

[26] Anjana P Das, Sabu M Thampi, "Fault-resilient localization for underwater sensor networks", Adhoc Networks, 55, 132-142, 2017.

[27] Eliyeh Mortazavi, Reza Javidan, Mohammad Javad Dehghani, Vali Kavoosi, "A robust method for underwater wireless sensor joint localization and synchronization”, Ocean Engineering, 137, 276-286, 2017.

[28] Jingjie Gao, Xiaohong She, Haiyan Wang, "A hybrid localization algorithm for multi-hop mobile underwater acoustic networks", 2-7, 2017.

[29] Patrick Carroll, Katherine Domrese, Hao Zhou, Shengli Zhou, "Doppler Aided localization of mobile nodes in an underwater distributed antenna system”, Physical Communication, 18, 49-59, 2016.

[30] Mukesh Beniwal, Rishi Pal Singh, Anju Sangwan, "A Localization Scheme for Underwater Sensor Networks Without Time Synchronization”, Wireless Pers Communication, 88,537-552,2016.

[31] P. M. Ameer, Lillykutty Jacob, Underwater localization using stochastic proximity embedding and multidimensional scaling. In. National Conference on Communications (NCC) 2013, 19:1679- 1690

[32] Ying Guo, Yutao Liu, "Localization for Anchor Free Underwater Sensor Networks", Computers and Electrical Engineering, 39, 1812-1821, 2013.

[33] Samedha S. Naik and Manisha J. Nene, "Effect of Sound Speed on Localization Algorithm for Underwater Sensor Networks", 541- 550, 2012.

[34] Dipali Parag Adhyapak1, Sridharan Bhavani2, Aparna Pradeep Laturkar, "Ant Based Cross Layered Optimization Protocol for Wireless Multimedia Sensor Network with Fuzzy Clustering”, Indonesian Journal of Electrical Engineering and Computer Science(IJEECS) Vol. 10, No. 3, June 2018, pp. 1303 1309.

[35] Subhashini. N, A. Brintha Therese, "Long Reach and High Capacity Hybrid Passive Optical Network", Indonesian Journal of Electrical Engineering and Computer Science (IJEECS) Vol. 11, No. 3, September 2018, pp. 891 897. 